\title{
EFFECTS OF ELECTRODE DEFORMATION OF RESISTANCE SPOT WELDING ON 304 AUSTENITIC STAINLESS STEEL WELD GEOMETRY
}

\author{
Nachimani Charde \\ Department of Mechanical, Material and Manufacturing Engineering, \\ Faculty of Engineering, University of Nottingham Malaysia Campus, \\ Jalan Broga, 43500 Semenyih, Selangor Darul Ehsan, Malaysia \\ Email: nachi.charde@nottingham.edu.my
}

\begin{abstract}
The resistance spot welding process is accomplished by forcing huge amounts of current flow from the upper electrode tip through the base metals to the lower electrode tip, or vice versa or in both directions. A weld joint is established between the metal sheets through fusion, resulting in a strong bond between the sheets without occupying additional space. The growth of the weld nugget (bond between sheets) is therefore determined from the welding current density; sufficient time for current delivery; reasonable electrode pressing force; and the area provided for current delivery (electrode tip). The welding current and weld time control the root penetration, while the electrode pressing force and electrode tips successfully accomplish the connection during the welding process. Although the welding current and weld time cause the heat generation at the areas concerned (electrode tip area), the electrode tips' diameter and electrode pressing forces also directly influence the welding process. In this research truncated-electrode deformation and mushrooming effects are observed, which result in the welded areas being inconsistent due to the expulsion. The copper to chromium ratio is varied from the tip to the end of the electrode whilst the welding process is repeated. The welding heat affects the electrode and the electrode itself influences the shape of the weld geometry.
\end{abstract}

Keywords: Spot welding; electrode deformation; electrode mushrooming.

\section{INTRODUCTION}

Resistance spot welding joins two or more sheets together when the areas concerned are melted using a high current flow. The basic parameters that produce a weld nugget are the welding current, weld time, electrode force and electrode tip (Aravinthan \& Nachimani, 2011). Although the welding current and weld time control the root penetration in the weld zone, the electrode tip and force finalize the geometry of the weld nuggets (Bower, Sorensen, \& Eager, 1990). Thus the upper and lower electrodes obviously have to be aligned in such a way that they enable appropriate weld geometry. Electrodes made of copper, chromium and carbon (class 3 ) are analyzed using stainless steel base metals. In this research paper, the geometry of the welded areas is analyzed with respect to the alignment of the electrode and electrode tip deformation.

\section{EXPERIMENTATION}

The stainless steel base metals were prepared in a rectangular shape with dimensions of length $=200 \mathrm{~mm}$, width $=25 \mathrm{~mm}$ and thickness $=1$ and $2 \mathrm{~mm}$. A pair of water-cooled 
(4 liters per minutes) truncated-type electrodes ( $5 \mathrm{~mm}$ in diameter) was used to join these base metals, as shown in Figure 1 (Rao, Liao, Tsai, Wang, \& Stevenson, 2009). A pair of test samples was initially placed at the top of the lower electrode (tip) of the welder with the samples overlaid by $60 \mathrm{~mm}$ over each other (lap joint), and then the initiating pedal was pressed. The heating process was started immediately after the squeezing cycles of the pneumatic-based electrode actuation ends. The welding current was then released in accordance with the given preset values. Thereafter the electrode pressing mechanism expended some time for cold working, and eventually returned to the home position of the upper electrode. These process controlling parameters (welding current, weld time and electrode pressing force) are set before the welding process starts, based on the manufacturers of the weld lobe. Table 1 lists the general description of the copper-based alloy-electrodes used in this analysis. The welded samples underwent macrograph testing and were later compared with simulation results obtained from the SORPAS resistance spot welding simulator. The electrode indentation was measured during macrograph analysis. Furthermore, the electrodes also underwent macrograph testing to analyze the micro structural changes.

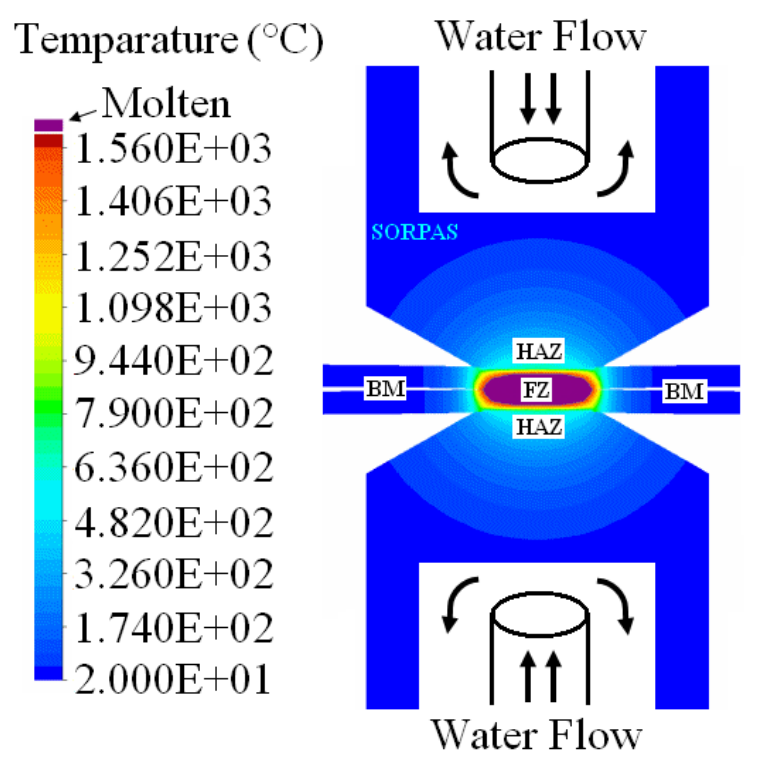

Figure 1. Welding process using truncated electrodes.

Table 1. Properties of CMW copper-based alloys.

\begin{tabular}{lc}
\hline CMW Alloy (Class 2) & CMW 3 (ME 14 Z) \\
\hline Condition & Cast Wrought \\
Principle Elements & Copper, Chromium \\
RWMA Alloy Number & 2.18200 \\
Rockwell Hardness (HRB) & $70-83 \mathrm{~B}$ \\
Electrical Conductivity \% IACS & $80-85$ \\
Ultimate Tensile Strength (PSI) & $55-75 \mathrm{k}$ \\
Elongation \% in 2" & $15-20$ \\
Permanent Softening Begins at & $500^{\circ} \mathrm{C}$ \\
\hline
\end{tabular}




\section{RESULTS AND DISCUSSION}

\section{Micro Indentation of Weld Geometry}

The geometry of the welded areas are firstly analyzed in terms of the micro indentation produced by the electrodes during the welding process. It was found that the indentation increases as the process parameters increased. When the welding current, weld time and electrode pressing force were increased from $6 \mathrm{kA} / 10$ cycles / $3 \mathrm{kN}$ to $8 \mathrm{kA} / 20$ cycles / $6 \mathrm{kN}$, the indentations of the weld zones appeared to increase proportionally, which is graphically presented in Figure 2.

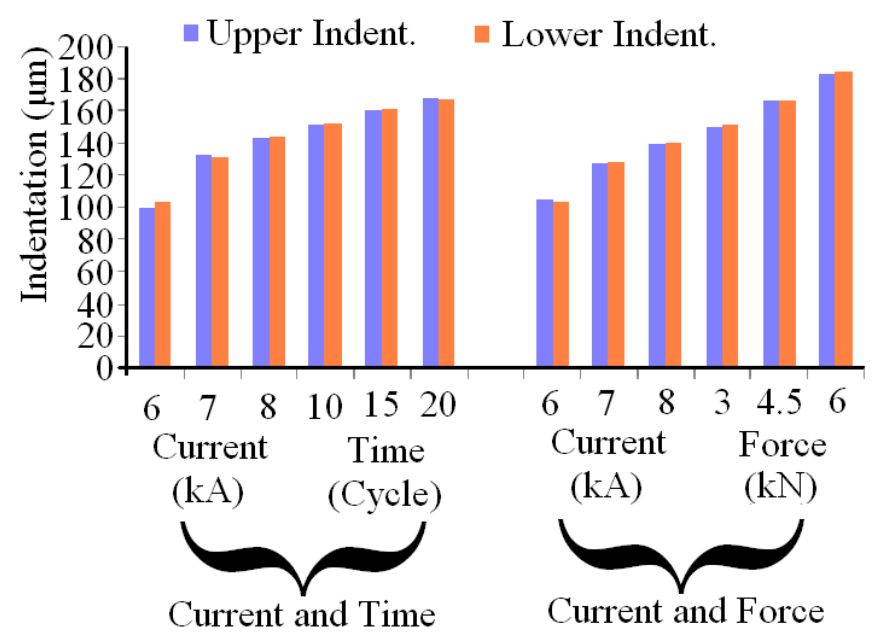

Figure 2. Effect of indentation for different currents, times and forces.

\section{Macro Views of Selected Weld Zones}

The welded zones were analyzed with respect to the alignment of the electrodes, and we found very few good welds using the pneumatic-based electrode actuation system; one of which is presented in Figure 3. The upper and lower electrodes were placed during the welding process so that a good weld was observed. The welded zone has an elliptical fusion zone (FZ), elliptical heat affected zone (HAZ) and supporting base metal (BM) (Hayat, 2011). Figure 4 shows the upper and lower electrodes indentations that obtained a good weld. There was no knock-on effects s on the weld surfaces because the electrodes were very new at the time of welding (Yeung \& Thornton, 1999). The misalignment of the upper and lower electrodes produces oblique weld borders, as shown in Figure 5. The electrode was misaligned during the squeezing cycles so that the weld bead partially deviated from its central position. The base metals $(2 \mathrm{~mm})$ also contained pores in their fusion zone; particularly along the center lines of both base metals (Shamsul \& Hisyam, 2007). This occurred due to the forging force which is not fully removable in AC spot welding. Figure 6 shows a weld bead resulting from a very high electrode pressing force during the welding process. This kind of weld nugget is naturally poor in strength because of the deeper indentations. 


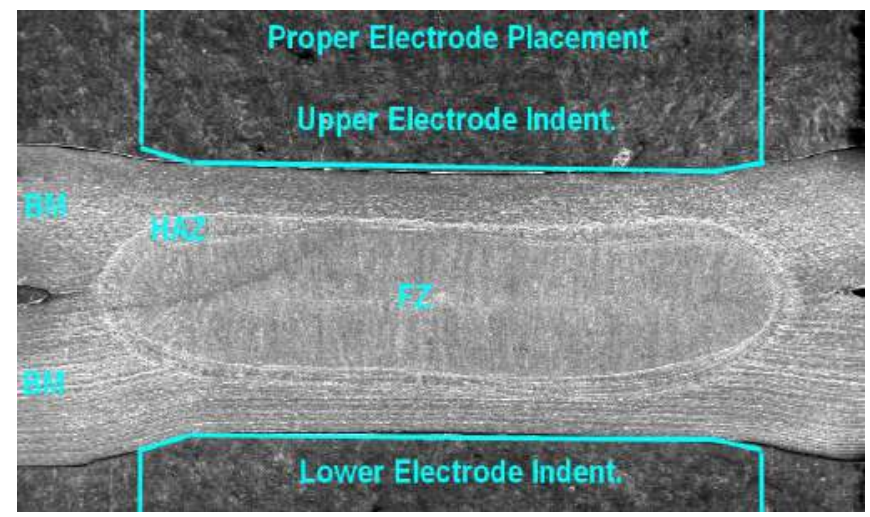

Figure 3. A good weld macrograph (internal structure).

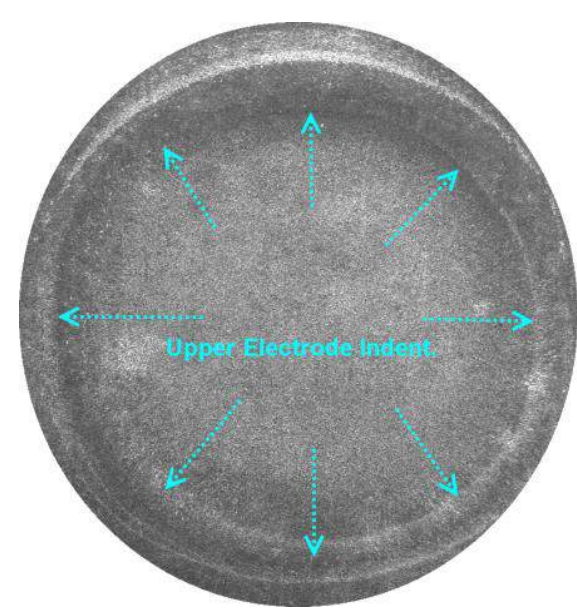

a) Upper indentation

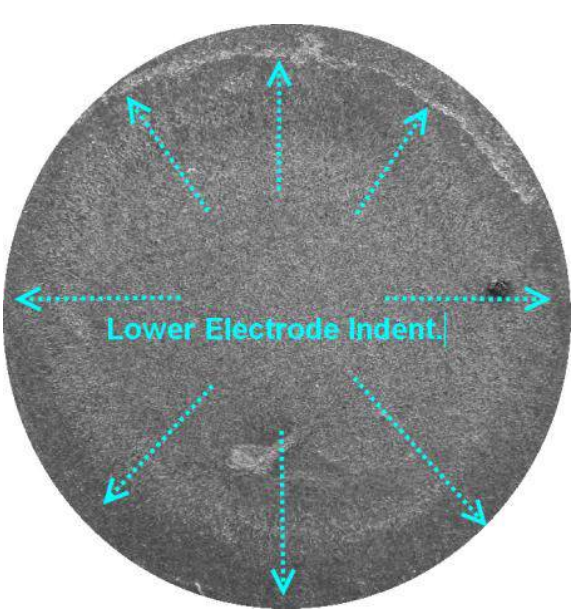

b) Lower indentation

Figure 4. A good weld macrograph (view of upper and lower indentations).

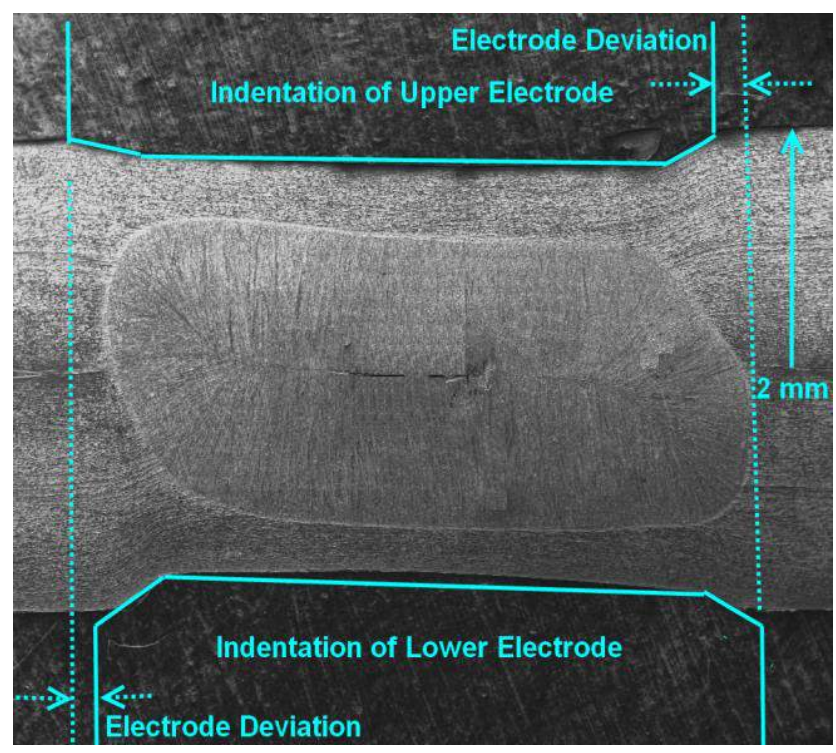

Figure 5. Misalignment weld macrograph (electrode misaligned). 


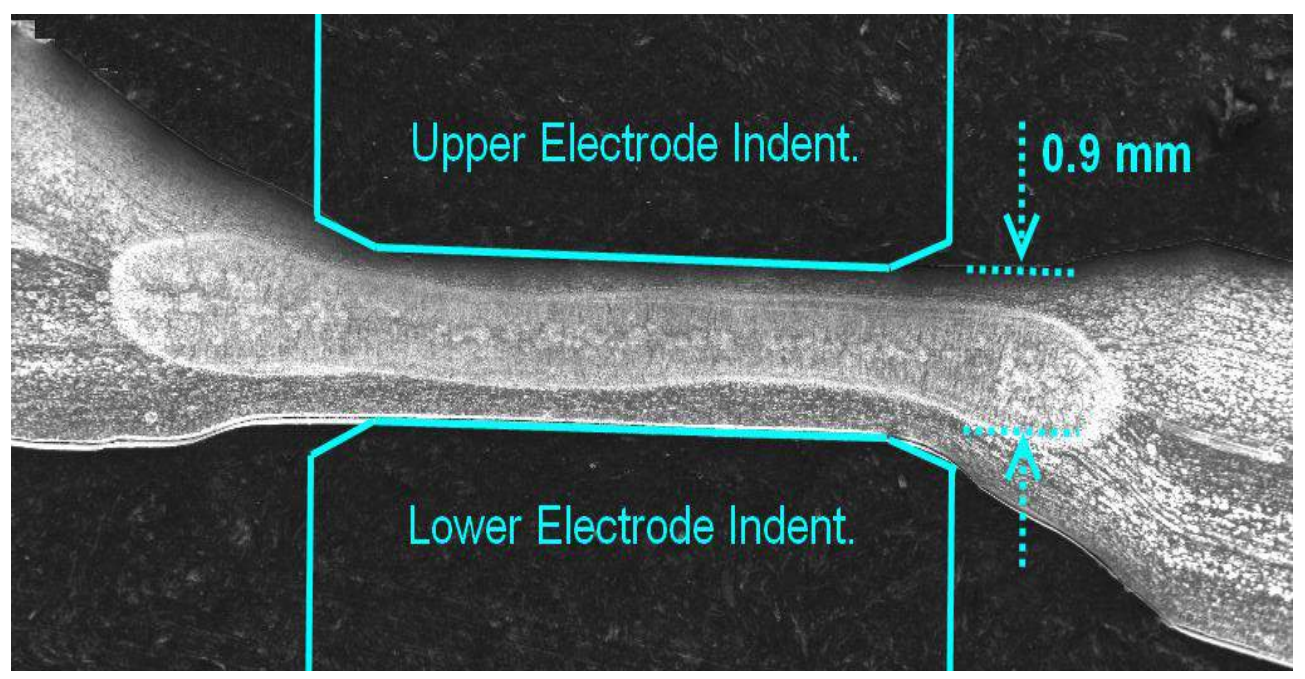

Figure 6. A poor weld macrograph (high electrode force).

The macrograph analysis was also carried out for the expulsion situations (Mehdi \& Abadi, 2010). One of which clearly showed the expulsion region that exists between the base metals. The misalignment of the electrodes' tips create a gap between the sheets from which the molten metals attempted to splash out due to the electrode pressing force during the welding process (Ozyurek, 2008). This kind of situation is shown in Figure 7. This can be avoided by ensuring that the electrode tips are frequently dressed. Finally, the worst case weld bead was noted when the current was increased to 10kA. Heavy molten metals splashed out from the fusion zone, leaving a noticeable void at the center. Figure 8 shows a heavily-damaged weld nugget.

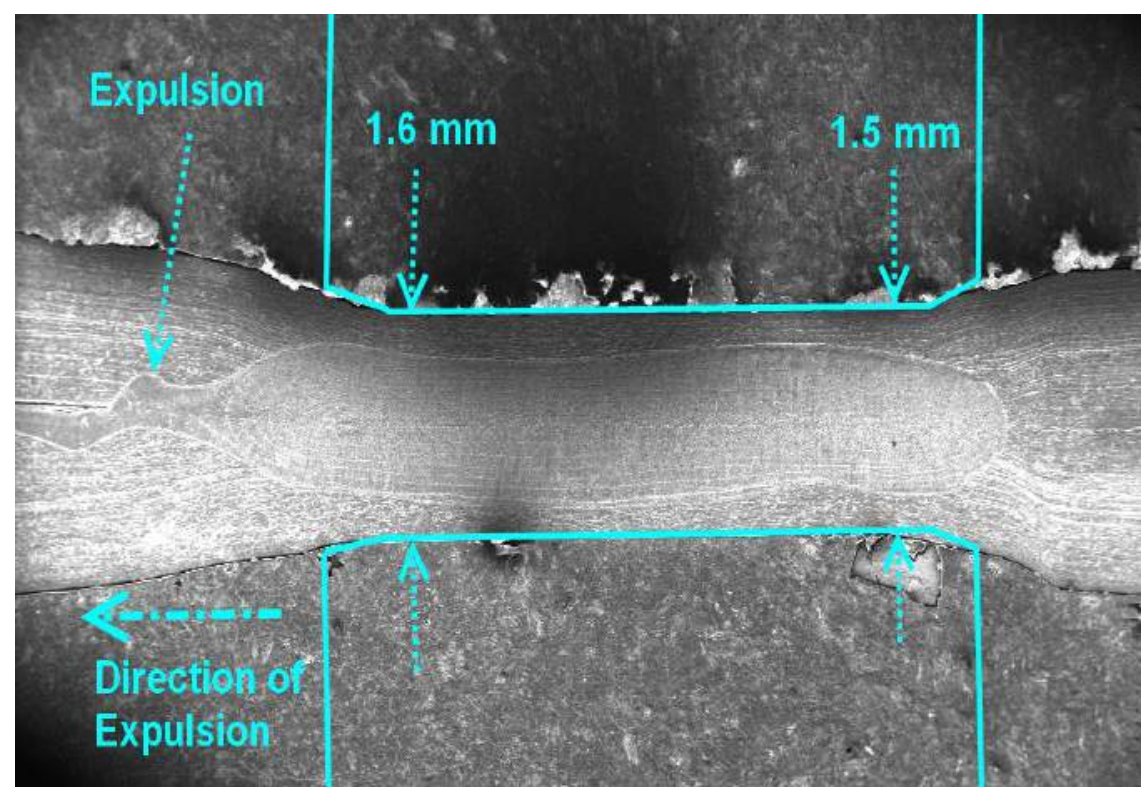

Figure 7. A poor weld macrograph (oblique electrode force). 


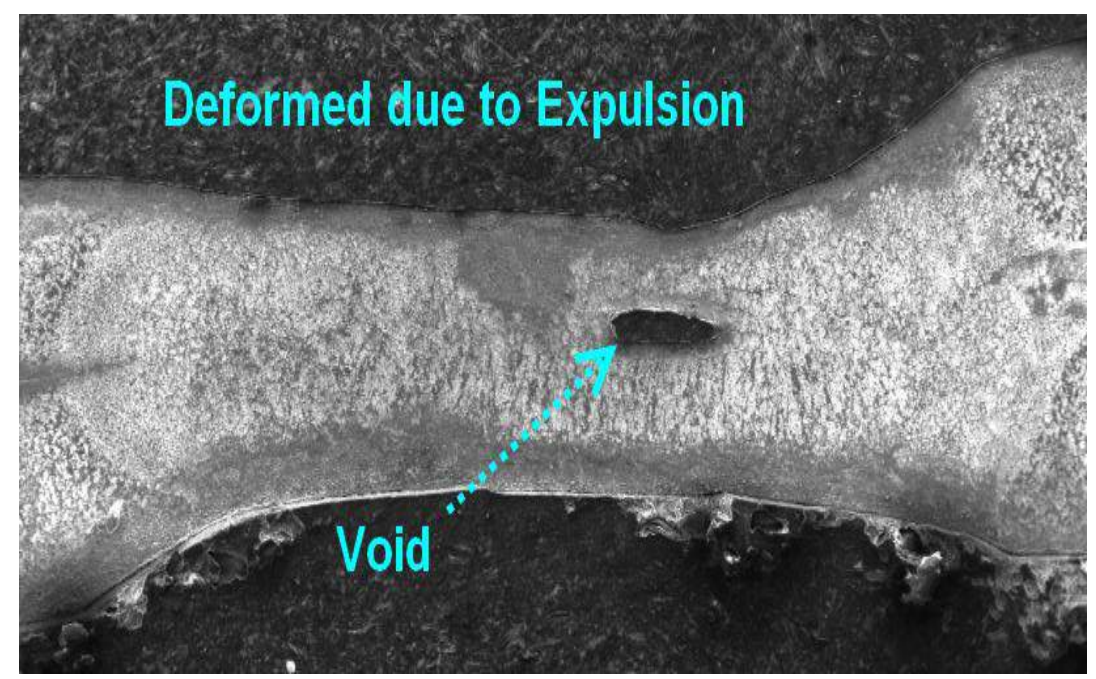

Figure 8. A very poor weld macrograph (heavy expulsion).

\section{Effect of Electrode Dressing}

Initally the nugget geometry was formed according to the truncated type electrodes as shown in Figure 9. Once it was dressed using an electrode dresser after 200 weld attempts, the weld nuggets' geometry became almost the same as dome type electrode welds (Figure 10). The simulation and experimental results are presented in Figures 9 and 10 for the truncated and dome types of electrode welds, respectively.

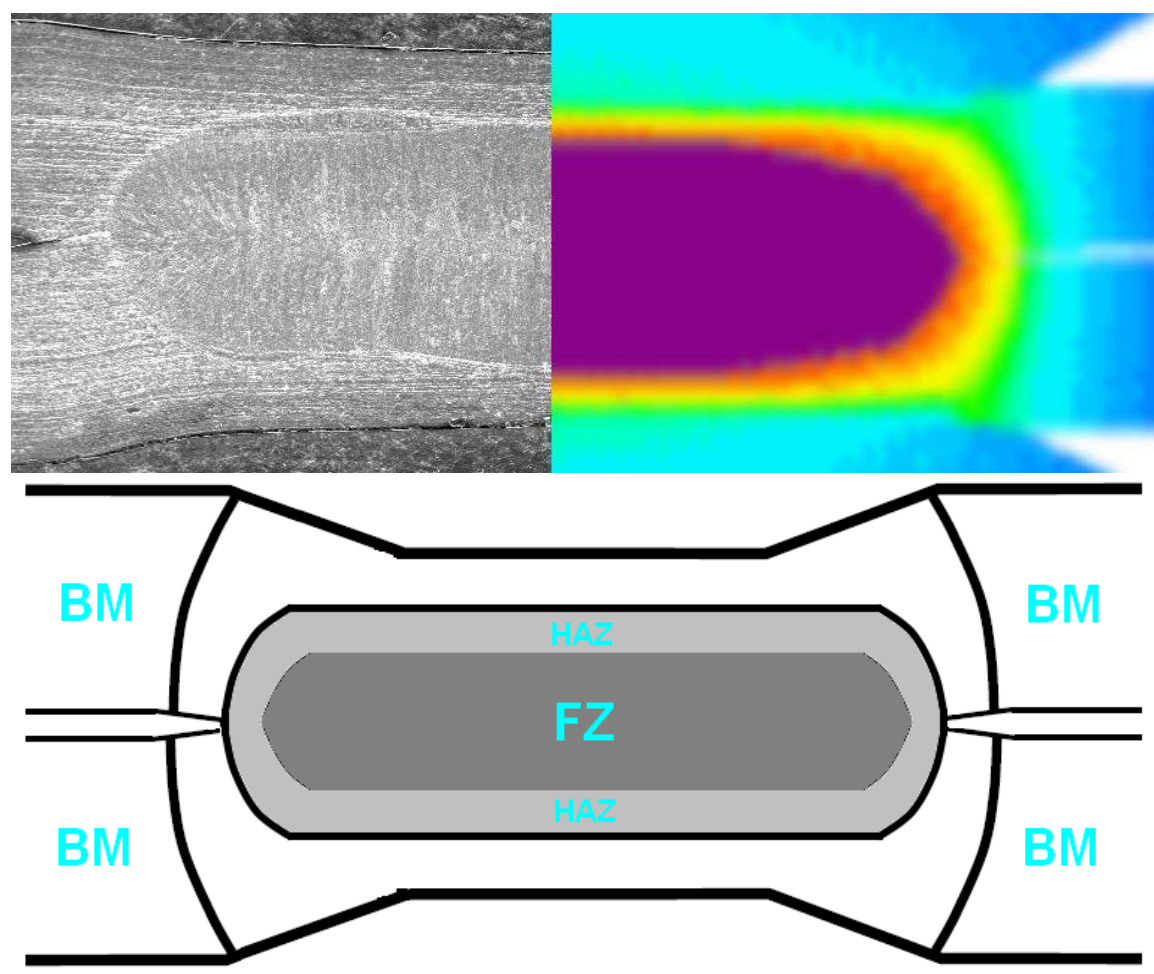

Figure 9. Truncated type weld nugget geometry (before dressing). 


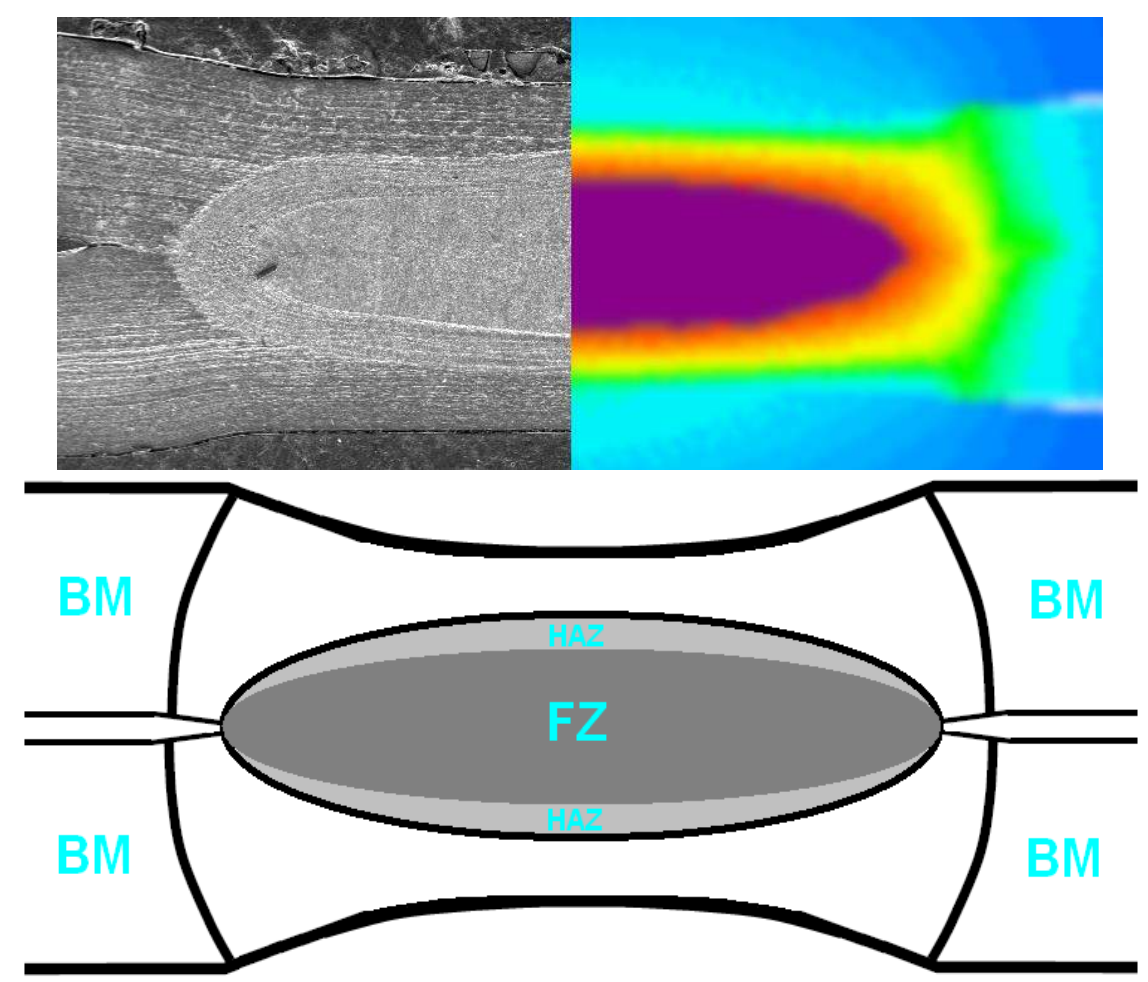

Figure 10. Dome type weld nugget geometry (after dressing).

\section{Electrode Mushrooming Effect}

The class two spot welding electrodes are made of copper and chromium according to the RWMA classification, it has a two-phase mixture of chromium and alpha copper. Basically the changes in the properties occur at elevated temperature due to the precipitation of chromium out of the solid solution (Chang \& Zhou, 2003). This is as noted in the micro structural view of the electrodes. As the number of welds increases, the mushrooming effect grows due to heat exposure at the electrode tips (Figure 11(a)). In this research the original electrode tip was $5 \mathrm{~mm}$ in diameter and it was mushroomed to $6.123 \mathrm{~mm}$ after 400 weld attempts. Another reading was taken at around 900 weld attempts, at which the tip was found to be approximately $7.458 \mathrm{~mm}$ (Figure 11(b)). The mushrooming effect was initially about $23 \%$ of the original diameter, but increased to $49 \%$ at 900 weld attempts regardless of the base metal materials. Thereby electrode wear and tear is an existing factor during the welding process which alters the diameter of the electrode tips.

Having considered the mechanical and chemical changes that occur to the electrode after 900 welds, it was SEM-scanned for structural changes (Figure 12). Table 2 lists the chemical changes recorded for three points, denoted A, B, and C. Point A was the electrode tip at which the base metals' molten heat $\left(1500^{\circ} \mathrm{C}\right)$ was directly exposed. Points $\mathrm{B}$ and $\mathrm{C}$ are the following locations leading to the electrode holder which are exposed to thermal expansion (Chen, Zhou, \& Scotchmer, 2005). The EDX results show that the carbon content is very high at the electrode tip compared to the other two regions. Moreover the chromium to copper ratio is also affected due to heat exposure, as shown in Table 2. The micro structural views show that chromium precipitation is higher at the tip (point $\mathrm{A}$, resulting in a dual phase alpha copper structure. The fast cooling rate at point $\mathrm{C}$ due to the water coolant inside the electrode 
prevents chromium precipitation and results in a single phase alpha copper structure. Point $\mathrm{B}$ has balanced itself between points $\mathrm{A}$ and $\mathrm{C}$.

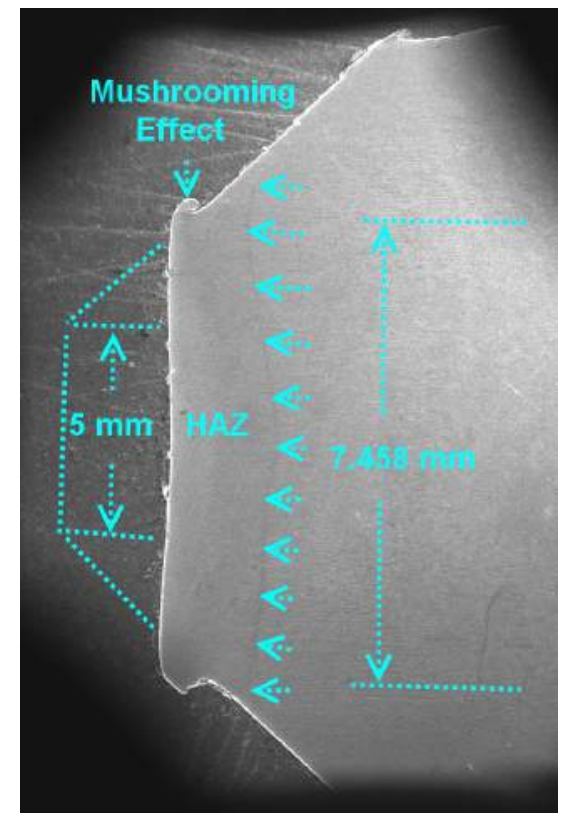

a) Macrograph of electrode tip

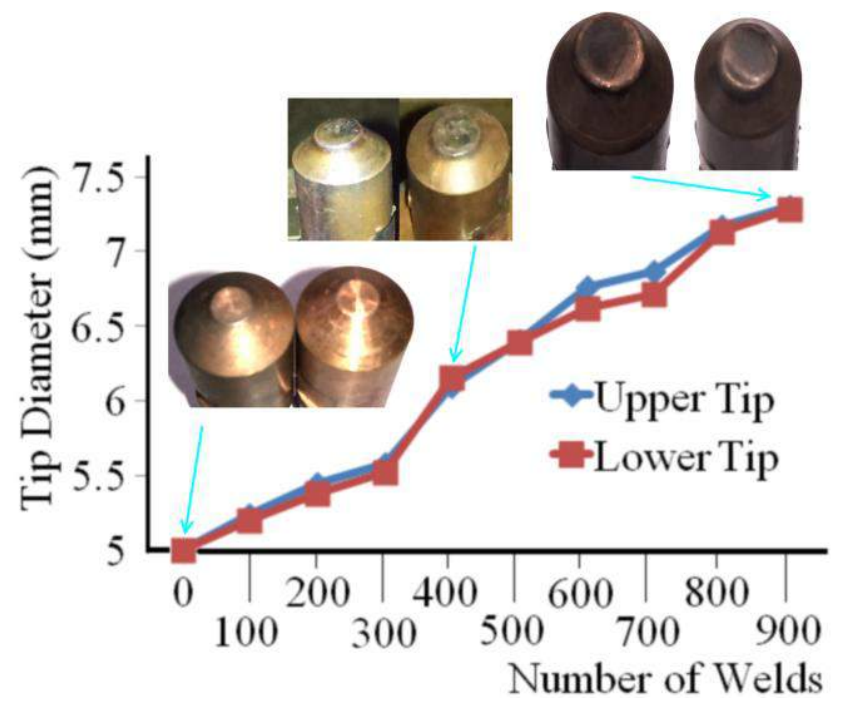

b) Increment in mushroom diameter

Figure 11. Electrode mushrooming effects.

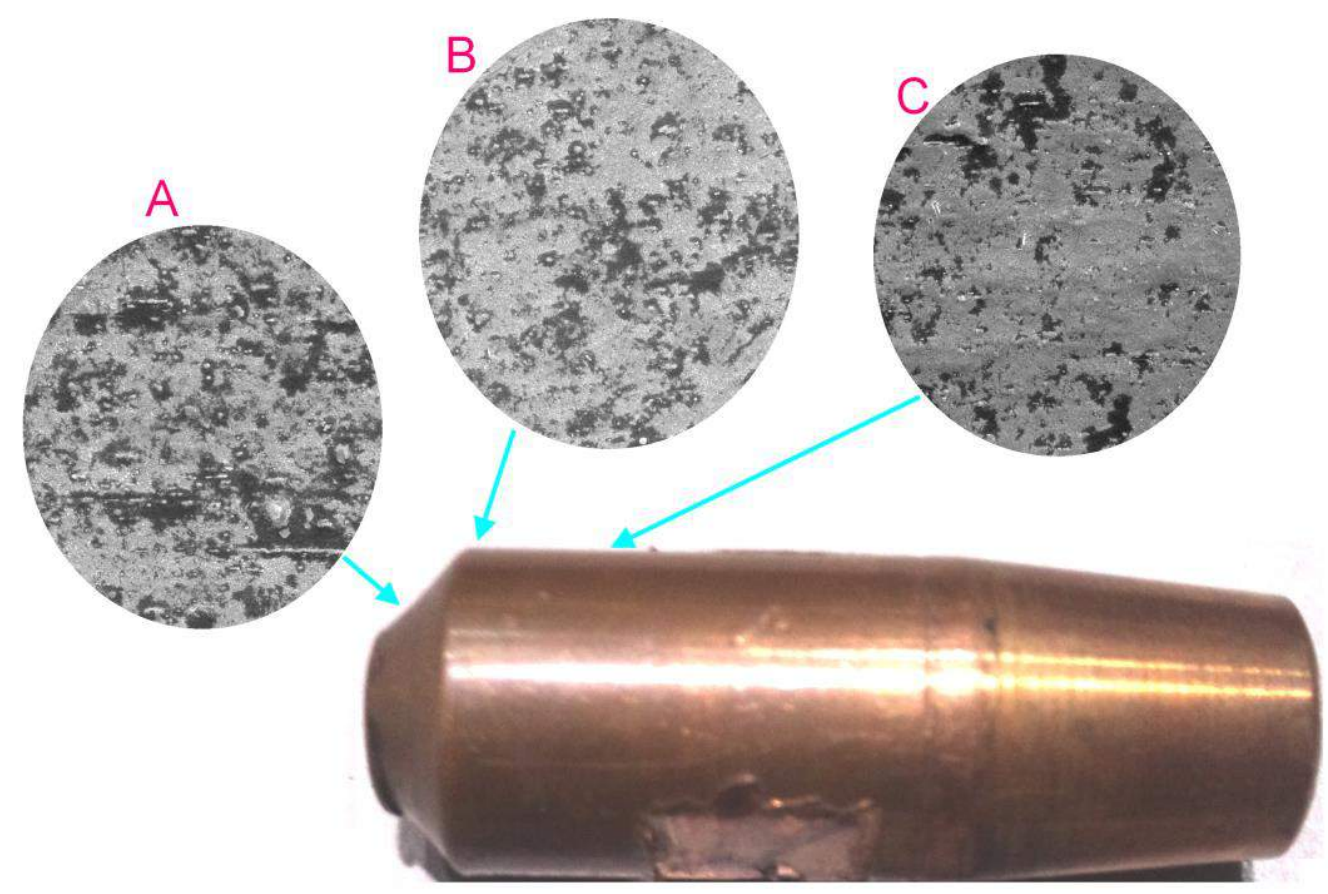

Figure 12. Electrode microstructural changes. 
Table 2. Chemical distribution of the electrode.

\begin{tabular}{lccc}
\hline Orbit 'K' & Point 'A' $(\mathrm{Wt} \%)$ & Point 'B'(Wt \%) & Point 'C'(Wt \%) \\
\hline Carbon $(\mathrm{C})$ & 12.8 & 13.5 & 15.13 \\
Chromium $(\mathrm{Cr})$ & 1.2 & 1.8 & 2.11 \\
Copper $(\mathrm{Cu})$ & 85.99 & 83.98 & 82.70 \\
\hline
\end{tabular}

\section{Optical Views of Selected Weld Zones}

The optical camera was used to capture some of the weld surfaces that developed before and after the electrode mushrooming effects. Figure 13(a) shows the weld surface that developed when the electrode was new, while Figure 13(b) represents the weld surfaces which developed after 900 welds without dressing. A good weld nugget surface has contour rainbow colors due to the heat expansion and an almost circular type of indentation. However, electrode mushrooming has created defect weld surfaces due to improper contact between the electrode and sheet, causing expulsion.

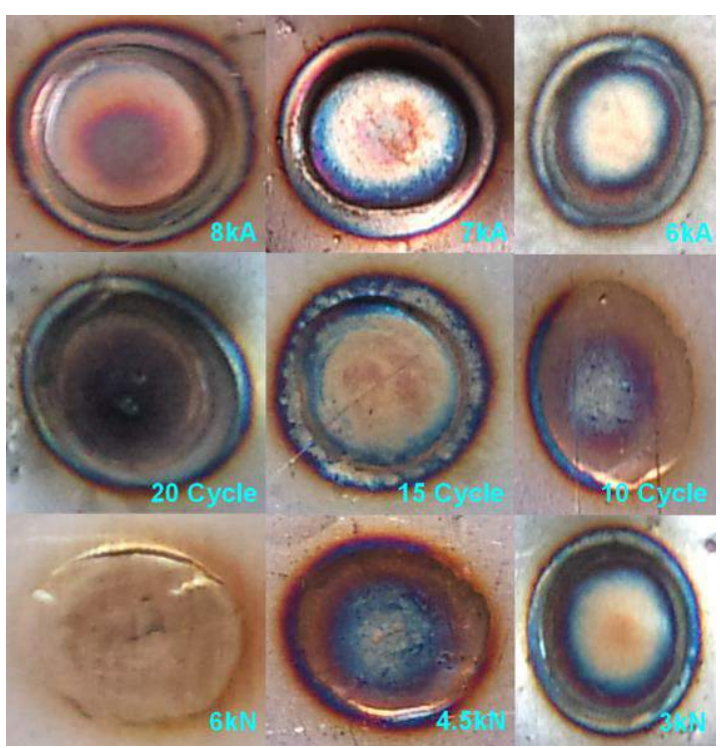

a) Good weld surfaces

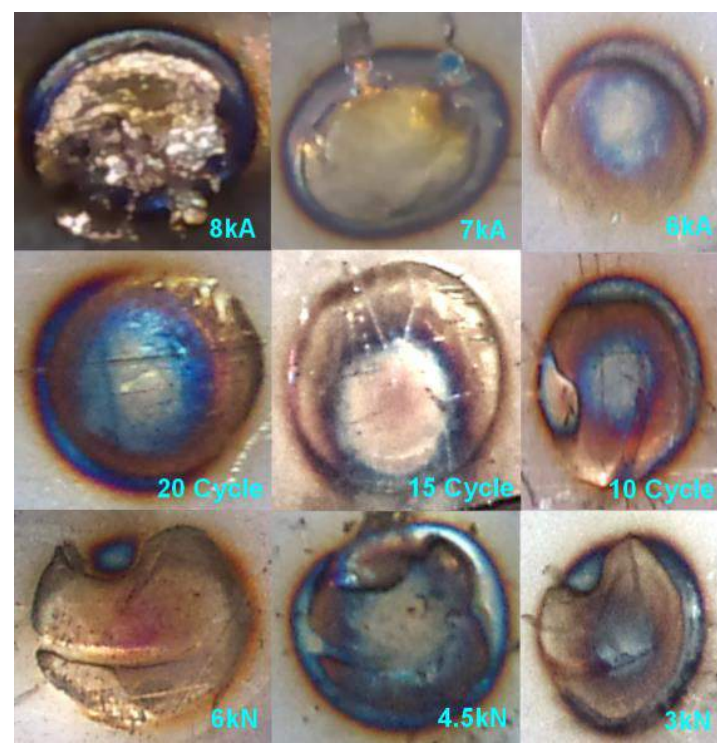

b) Defect weld surfaces

Figure 13. Electrode microstructural changes.

\section{CONCLUSIONS}

This paper examined weld zone geometry using stainless steel base metals with respect to electrode alignment and its mushrooming effects. The research has concluded that:

i) Electrode indentation increases as the process parameters (current, time and force) are increased.

ii) Electrode alignment plays an important role in the weld geometry, regardless of thickness.

iii) A proper weld zone has an elliptical weld nugget consisting of elliptical fusion and heat affected zones.

iv) Misalignment of electrodes causes expulsion which leads to poor weld zones.

v) Electrode dressing changes the nuggets' weld pattern. In this experiment it 
changes from a truncated to dome type of weld.

vi) The initial welding process up to 400 times increased the electrode tip diameter by about $23 \%$.

vii) Further welding up to 900 times increases the electrode tip diameter by about $49 \%$.

viii) A chemical and mechanical imbalance was determined in the electrode after 900 welds.

\section{ACKNOWLEDGMENTS}

I would like to thank the Ministry of Science, Technology and Innovation, Malaysia (MOSTI) for their financial support during the experiments. This research is an extension of my PhD research work at Nottingham University Malaysia Campus.

\section{REFERENCES}

Aravinthan, A., \& Nachimani, C. (2011). Analysis of spot weld growth on mild and stainless steel. Welding Journal, 143-147.

Bower, R. J., Sorensen, C. D., \& Eager, T. W. (1990). Electrode geometry in resistance spot welding. Welding Journal, 45-51.

Chang, B. H., \& Zhou, Y. (2003). Numerical study on the effect of electrode force in small-scale resistance spot welding. Journal of Materials Processing Technology, 139, 635-641.

Chen, Z., Zhou, Y., \& Scotchmer, N. (2005). Coatings on resistance welding electrodes to extend life. SAE International, 1-4.

Hayat, F. (2011). The effects of the welding current on heat input, nugget geometry, and the mechanical and fractural properties of resistance spot welding on $\mathrm{Mg} / \mathrm{Al}$ dissimilar materials. Materials and Design, 32, 2476-2484.

Mehdi, M. M., \& Abadi, M. P. (2010). Correlation between macro/micro structure and mechanical properties of dissimilar resistance spot welds of AISI 304 austenitic stainless steel and AISI 1008 low carbon steel. MJoM (Association of Metallurgical Engineers of Serbia), 16(2): 133-146.

Ozyurek, D. (2008). An effect of weld current and weld atmosphere on the resistance spot weld ability of 304L austenitic stainless steel. Materials and Design, 29(3), 597-603.

Rao, Z. H., Liao, S. M., Tsai, H. L., Wang, P. C., \& Stevenson, R. (2009). Mathematical modeling of electrode cooling in resistance spot welding. Welding Journal, 111119.

Shamsul, J. B., \& Hisyam, M. M. (2007).Study of spot welding of austenitic stainless steel type 304. Journal of Applied Sciences Research, 3(11), 1494-1499.

Yeung, K. S., \& Thornton, P. H. (1999). Transient thermal analysis of spot welding electrodes. Welding Journal, 1-6. 